\title{
ANÁLISE QUANTIQUALITATIVA DA NORMA DE DESEMPENHO (NBR № 15.575/2013) E PRINCIPAIS DESAFIOS DA IMPLANTAÇÃO DO NÍVEL SUPERIOR EM EDIFICAÇÃO RESIDENCIAL DE MULTIPAVIMENTOS
}

\author{
QUALI-QUANTITATIVE ANALYSIS OF THE BRAZILIAN \\ PERFORMANCE STANDARD (NBR no. 15,575/2013) AND \\ MAIN CHALLENGES FOR UPPER LEVEL IMPLEMENTATION \\ ON RESIDENTIAL MULTIFLOOR BUILDINGS
}

\section{Jonas Leonardo Pessanha de Souza', Andrea Parisi Kern', Bernardo Fonseca Tutikian'}

RESUMO: Com o objetivo de melhorar o desempenho das edificações, seguindo tendência mundial, a NBR n 15.575/2013, conhecida como Norma de Desempenho (ND), é dividida em seis partes e define critérios mínimos, intermediários e superiores, assim como métodos de avaliação do desempenho das edificações habitacionais. Devido à complexidade envolvida no atendimento à norma, este artigo apresenta resultados de um estudo de caso realizado durante a etapa de produção em uma obra residencial de multipavimentos que buscou atender a ND no nível superior. O objetivo do trabalho consiste em uma análise qualiquantitativa dos requisitos e critérios de desempenho da norma e a identificação das principais alterações realizadas no edifício em questão, em relação a obras tradicionalmente realizadas pela empresa construtora, tendo em vista o atendimento da ND. O método de pesquisa envolveu análise de documentos (ND, projetos, manuais, memoriais), entrevistas com projetistas e construtores e observações no canteiro de obras. Os resultados indicam que dos 155 critérios, apenas 26 estabelecem três níveis de atendimento: inferior, intermediário e superior. A análise quantitativa, em termos de complexidade de atendimento, indica que a parte da norma mais complexa de ser atendida consiste na relativa aos requisitos gerais, seguido por sistemas estruturais, sistemas de pisos e sistemas de vedação. Embora o número de critérios com três níveis seja pouco representativo (16\%), a diferença de desempenho entre os níveis inferior e superior é expressiva e pode representar grande diferencial para a edificação no atendimento do nível superior. As principais mudanças e desafios para a implantação da ND, nível superior na obra estudada, consistem no expressivo número de ensaios realizados no papel, relevante da Instituição Técnica Avaliadora (ITA) e a adoção de novas tecnologias ou materiais não utilizados em obras anteriores pela empresa construtora.

PALAVRAS-CHAVE: Implantação de Norma; Norma de Desempenho; NBR nº $15.575 / 2013$.

ABSTRACT: In order to improve buildings performance, following a worldwide trend, NBR no. 15,575/2013, known as Performance Standard (PS), is composed of six parts and defines minimum, intermediate and superior criteria and methods for evaluating residential buildings efficiency. Due to the complexity involved in meeting the standard, this article presents results of a case study carried out during the production stage of a multi-floor residential project that sought to meet PS at the upper level. This research aimed to analyze quanti-qualitatively the standard requirements and criteria of performance and to identify the main changes made in the building studied, in relation to works traditionally carried out by the construction company. The research

\section{How to cite this article:}

SOUZA, J. L. P.; KERN, A. P.; TUTIKIAN, B. F. Análise quantiqualitativa da norma de desempenho (NBR no 15.575/2013) e principais desafios da implantação do nível superior em edificação residencial de multipavimentos. Gestão e Tecnologia de Projetos, São Carlos, v. 13, n. 1, p. 127-144, 2018. http://dx.doi.org/ 10.11606/gtp.v13i1.133842

\author{
Fonte de financiamento: \\ Coordenação de \\ Aperfeiçoamento de Pessoal \\ de Nível Superior (Capes), \\ Programa de Suporte à \\ Pós-Graduação de Instituições \\ de Ensino Particulares \\ (Prosup) \\ Conflito de interesse: \\ Declaram não haver \\ Submetido em: 21/06/2017 \\ Aceito em: 12/12/2017
}

Universidade do Vale do Rio dos Sinos 
method involved document analysis (PS, designs, manuals, memorials), interviews with designers and builders, and observations of the construction site. The results indicate that out of 155 criteria, only 26 established the three levels of attendance: lower, intermediate and upper. The quantitative analysis, in terms of attendance complexity, indicates that the most complex part consists on general requirements, followed by: structural systems, floor systems and sealing systems. Although the number of criteria with three levels is not very representative (16\%), the performance difference between lower and upper levels is expressive and can represent a great differential for a better service. The main changes and challenges for the implementation of PS consisted on significant number of laboratory experiments, the relevant role of Technological Evaluation Institutes, and the adoption of new technologies or materials not used previously by the construction company.

KEYWORDS: NBR no. 15,575/2013; Performance Standard; Upper Level; Building Certification.

\section{INTRODUÇÃO}

A preocupação com o desempenho de produtos teve início no período da Segunda Guerra Mundial, e foi voltada à fabricação de produtos da indústria bélica para atender exigências de segurança estrutural (BORGES; SABBATINI, 2008). Na indústria da construção, o conceito de desempenho de edificações vem sendo estudado desde a década de 1960, e o livro Savoir batir: habitabilite, durabilite, economie des batiments, (Saber construir: habitabilidade, durabilidade, economia dos edifícios) de Gerard Blachére é reconhecido como uma importante publicação no tema, que conceitua desempenho das edificações como o comportamento em uso durante determinada vida útil. (BlachÉre,1967).

No Brasil, o desempenho das construções começou a estar na pauta de discussão a partir da década de 1980, fortemente ligado à habitação, tendo em vista o significativo aumento do déficit habitacional e suas consequências (construções irregulares e favelas) (Serra, 1989; Maricato, 1999). Esse cenário desencadeou o mercado de provisão habitacional, especialmente o de Empreendimentos de Habitação de Interesse Social (EHIS) (Bonduki, 2004). Nesse contexto, novos sistemas construtivos foram utilizados e a adoção de tecnologias muitas vezes desapropriadas levou a graves prejuízos como patologias e altos custos de manutenção (Gonçalves et al., 2003). Nessa época, o Instituto de Pesquisas Tecnológicas de São Paulo publicou "Critérios mínimos de desempenho", que consiste num dos primeiros documentos sobre desempenho para avaliação dos sistemas construtivos de habitações no Brasil (Borges, 2008).

Mais tarde, a implantação de políticas públicas para diminuir o déficit habitacional e fomentar a indústria da construção civil impulsionou um crescimento e aquecimento do setor. No entanto, segundo Nakamura (2012), inúmeros proprietários queixavam-se de vícios construtivos e baixa qualidade das construções entregues. A partir do ano 2000, baseada no conceito de desempenho, a Caixa Econômica Federal financiou um projeto para a criação de um método de avaliação de sistemas construtivos inovadores, que resultou na publicação da NBR no 15.575/2010 - Edifícios habitacionais de até cinco pavimentos - Desempenho. Tendo em vista os impactos nas práticas de projeto, construção e cadeia de fornecedores, o documento ficou em discussão pública e sofreu algumas revisões até entrar em vigor em 2013, com o título NBR nº 15.575/2013 - Edifícios habitacionais - Desempenho, também conhecida como Norma de Desempenho (ND).

O objetivo desta norma é estabelecer exigências para edificações habitacionais quanto ao seu comportamento em uso e necessidades dos usuários. A ND contém requisitos qualitativos, critérios quantitativos ou premissas e métodos de avaliação que permitem a conferência do seu cumprimento (ASSOCIAÇÃO BRASILEIRA DE NORMAS TÉCNICAS, 2013). 
Esses critérios estão definidos em três níveis: mínimo, intermediário e superior. A partir da adoção da norma, espera-se melhoria na qualidade das construções, segundo a Caixa Econômica Federal (CAIXA ECONÔMICA FEDERAL, 2014), maior financiadora habitacional do país, e alega exigir seu atendimento em contratos.

Essa norma define os níveis de desempenho mínimos, independente dos materiais e métodos construtivos utilizados, portanto, difere da abordagem prescritiva da maioria das normas em vigor. Assim, a partir da abordagem de desempenho, a ND incentiva o desenvolvimento tecnológico, a criação de novos sistemas e a melhoria dos já consagrados. Foliente (2000) indica que essa mudança de abordagem prescritiva para desempenho é um esforço mundial para a melhoria das normas e códigos da construção civil. Segundo o autor, a abordagem por desempenho pode garantir inovação, melhoria, confiabilidade nos resultados e melhor comparação entre sistemas.

$\mathrm{O}$ atendimento às normas em vigor é obrigatório e previsto na legislação. Por exemplo, está definido na Lei $\mathrm{n}^{\circ}$ 8.078/1990, Código de Defesa do Consumidor, que é proibido ao fornecedor colocar no mercado qualquer produto ou serviço em desacordo com as normas técnicas (Art. 39), estando sujeito à multa, interdição e a outras penalidades (Art. 18). Já a Lei $\mathrm{n}^{\circ}$ 8.666/1993, Lei das Licitações, obrigatória para contratações realizadas por órgãos públicos, estipula que os projetos devem estar de acordo com as normas técnicas.

A NBR n ${ }^{0}$ 15.575/2013 é dividida em partes que se relacionam aos sistemas que compõem a edificação (estruturas, pisos, vedações, coberturas e instalações hidrossanitárias), e organizada por aspectos de desempenho, que são agrupamentos de critérios técnicos em relação à determinada função desejada (segurança estrutural, segurança contra incêndio, durabilidade, desempenho térmico, desempenho acústico e outros). A questão ambiental é tratada pela Norma a partir da sugestão da otimização de materiais e recursos naturais. Numa perspectiva mais ampla, edificações que atendam à ND tendem a diminuir a necessidade de reformas, e evitam a geração de resíduos de construção e demolição (RCD), pois devem atender aos critérios de durabilidade e manutenibilidade.

A ND é ampla em escopo e atrelada ao atendimento de outras normas. Além disso, possui abordagem diferenciada à tradicional (prescritiva), portanto, pode-se inferir que há considerável nível de complexidade em seu atendimento. É necessário ainda identificar que os critérios da norma possuem interdependência de acordo com a função e parte da edificação. Embora em vigor há quatro anos, existe pouca bibliografia sobre o tema. Portanto, o objetivo geral deste estudo é realizar uma análise qualiquantitativa da norma, em temos de critérios e aspectos de desempenho, e identificar os principais desafios na implantação da ND nível superior em edificação residencial de multipavimentos.

\section{ABORDAGEM DE DESEMPENHO - CARACTERÍSTICAS, HISTÓRIA E PANORAMA INTERNACIONAL}

A (ND) foi desenvolvida pela Associação Brasileira de Normas Técnicas (ABNT), com participação de setores envolvidos na cadeia da construção civil, como projetistas, fabricantes, fornecedores, usuários, universidades, laboratórios, entre outros. A Norma está dividida em seis partes: NBR $\mathrm{n}^{\circ}$ 15.575-1 - requisitos gerais; NBR $n^{0}$ 15.575-2 - sistemas estruturais; NBR $\mathrm{n}^{0}$ 15.575-3 - sistemas para pisos; NBR n ${ }^{0} 15.575-4$ - sistemas de vedações verticais; NBR $n^{0}$ 15.575-5 - sistemas de coberturas; e NBR $n^{0} 15.575$ 6 - sistemas hidrossanitários. O desempenho desses sistemas depende das características dos materiais utilizados e suas ligações, das técnicas construtivas empregadas e da capacitação da mão de obra executiva, como observa-se no centro da Figura 1, que também ilustra as partes da norma e as relações que resultam no desempenho. 
Figura 1: Características e divisões da norma de desempenho

Fonte: Souza (2016)

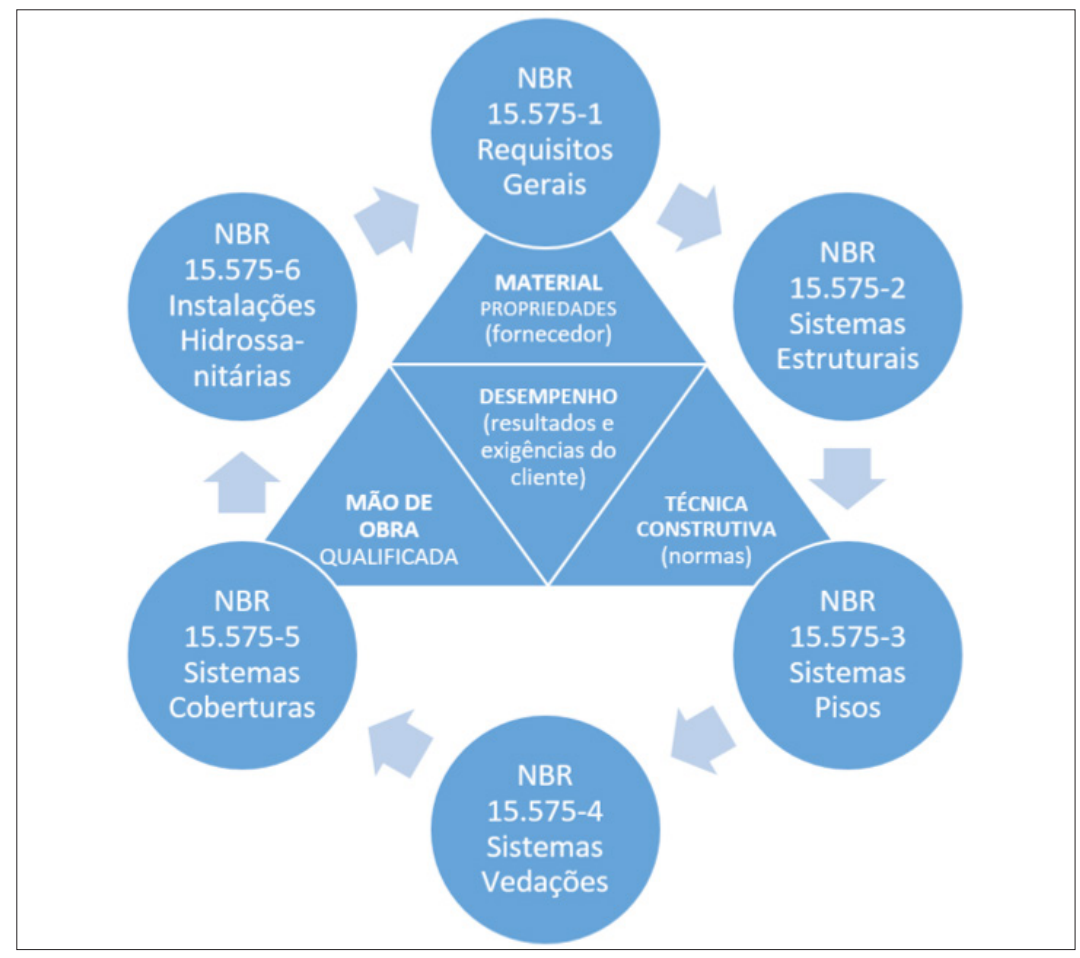

A ND apresenta abordagem focada nos resultados desejados, enquanto a abordagem prescritiva, utilizada na maioria das normas técnicas, indica as soluções aceitáveis através do conhecimento empírico dos materiais utilizados. Logo, as normas prescritivas tendem a ser mais fáceis de ser aplicadas e controladas, no entanto geram dúvidas quanto ao seu desempenho, principalmente ao se comparar sistemas diferentes (FOLIENTE, 2000).

Assim, a abordagem de desempenho é relevante, visto que é preciso garantir o adequado desempenho de cada parte, a importância de comparação de resultados entre diferentes sistemas, o impulso ao desenvolvimento dos sistemas atuais e a criação de novas tecnologias (FOLIENTE, 2000).

Em 1925, foi publicado nos Estados Unidos um relatório intitulado Prática recomendada para arranjo de códigos de construção, que dizia: "Sempre que possível, os requisitos devem ser expressos em termos de desempenho, com base em resultados de ensaios para condições de serviço, em vez de em dimensões, métodos ou materiais específicos” (FOLIENTE, 2000).

Segundo Blachére (1967), na década de 1960, o Council International for Building - CIB (Conselho Internacional para Edificação) começou os primeiros debates acerca de desempenho nas edificações. Em 1970, o CIB criou a comissão de trabalho CIB W60 The performance concept in building $(O$ conceito de desempenho na edificação) com o objetivo de definir o desempenho dos edifícios em âmbito internacional.

Desde 1980 são lançadas normas da Internacional Standards Organization - ISO (Organização Internacional de Normas) com o enfoque de desempenho Performance standards in buildings (Norma de desempenho em edificações), cujo conceito vem sendo ampliado a cada edição; ISO 6240/1980 - Performance standards in building: contents and presentation (Normas de Desempenho em Edificações: conteúdo e apresentação); ISO 6241/1984 - Performance standards in buildings: principles for their preparation and factors to be considered (Normas de Desempenho em Edificações: princípios e fatores a serem considerados); e ISO 7162/1992 - Performance standards in buildings: contents and format of standards for evaluation of performance considered (Normas de Desempenho em Edificações: conteúdo e formato dos padrões para avaliação do desempenho considerado) (GONÇALVES et al., 2003). 
Na Europa tem-se desenvolvido, através da Economic Commission for Europe-ECE (Comissão EconômicaparaEuropa), vários Compendium ofmodel provisions for building regulations (Compêndio de modelos de disposições para regras de construção) que, desde 1984, já utilizam requerimentos em desempenho, além dos eurocódigos como o EN 1990 de 2002 (bases para projetos estruturais), através do Comité Européen de Normalisation - CEN (Comitê Europeu de Normas).

Em 1994, o International Code Council - ICC (Conselho Internacional de Normas) desenvolveu o único código de construção dos Estados Unidos, o ICC Performance code for buildings and facilities (Código de desempenho para edifícios e instalações). No Canadá, em 2005, foi publicado o Objective-based bulding code (Código baseado no objetivo do edifício). Desde 1997, o ISO/TC 59/SC 15 - Technical Committe 59/Standards Catalogue 15 - Performance description of houses (Comitê Técnico $n^{o}$ 59, Catálogo de Padrões $n^{o}$ 15 - Descrição de desempenho das casas), que desenvolve normas de desempenho com participação de diversos países (8 países participantes e 11 em observação), a exemplo da ISO 15.928 em estágio de publicação (estágio 60.60). A Espanha criou o Código Técnico das Edificações (CTE), em 2006 (SILVA et al., 2014).

A discussão sobre a ND brasileira iniciou de um projeto de pesquisa financiado pela Caixa, em 2000, denominado Normas Técnicas para Avaliação de Sistemas Construtivos Inovadores, que partiu de trabalhos publicados pelo IPT (Instituto de Pesquisas Tecnológicas - São Paulo) de 1981 a 1998, e o Manual de avaliação da Caixa, de 2000. Em 2008, a Norma foi publicada para aplicação em edifícios habitacionais de até cinco pavimentos. Porém, após diversas reavaliações, foi publicada em 19 de fevereiro de 2013, passando a ser exigida a partir de 19 de julho de 2013 para todas as edificações residenciais.

A Tabela 1 resume o histórico das principais iniciativas nacionais e internacionais de documentos com enfoque em desempenho.

Tabela 1: Histórico das principais iniciativas internacionais de normas de desempenho

\begin{tabular}{|c|c|c|c|c|c|}
\hline Ano & 1925 & 1960 (década) & $\begin{array}{c}1980 \\
\text { (década) }\end{array}$ & 1984 & 1994 \\
\hline Origem & EUA & Internacional & Internacional & Europa & EUA \\
\hline Organização & - & CIB & ISO & ECE & ICC \\
\hline Documento & $\begin{array}{l}\text { Prática recomendada } \\
\text { para arranjo } \\
\text { de códigos de } \\
\text { construção }\end{array}$ & $\begin{array}{c}\text { Comissão CIB } \\
\text { W60 - Conceito } \\
\text { de desempenho na } \\
\text { edificação }\end{array}$ & $\begin{array}{c}\text { ISO } 6240 / 1980 \text { e ISO } \\
6241 / 1984\end{array}$ & $\begin{array}{c}\text { Compêndio } \\
\text { de modelos } \\
\text { de disposições } \\
\text { para regras de } \\
\text { construção }\end{array}$ & $\begin{array}{c}\text { Código de } \\
\text { desempenho para } \\
\text { edifícios e instalações }\end{array}$ \\
\hline Observação & $\begin{array}{l}\text { Sempre que possível } \\
\text { os requisitos devem ser } \\
\text { expressos em termos } \\
\text { de desempenho }\end{array}$ & $\begin{array}{c}\text { Definir o } \\
\text { desempenho dos } \\
\text { edifícios em âmbito } \\
\text { internacional }\end{array}$ & $\begin{array}{c}\text { Normas de } \\
\text { desempenho em } \\
\text { edificações }\end{array}$ & $\begin{array}{l}\text { Conjunto de } \\
\text { soluções e regras } \\
\text { para construção }\end{array}$ & $\begin{array}{l}\text { Código único de } \\
\text { construção dos } \\
\text { Estados Unidos }\end{array}$ \\
\hline Ano & 2002 & 2005 & 2006 & 2013 & 2015 \\
\hline Origem & Europa & Canadá & Espanha & Brasil & Internacional \\
\hline Organização & CEN & - & - & ABNT & ISO \\
\hline Documento & $\begin{array}{l}\text { Eurocodes, ex. EN } \\
\text { 1990/2002 (bases } \\
\text { para projetos } \\
\text { estruturais) }\end{array}$ & $\begin{array}{l}\text { Código baseado no } \\
\text { objetivo do edifício }\end{array}$ & $\begin{array}{l}\text { Código técnico das } \\
\text { edificações }\end{array}$ & $\begin{array}{l}\text { NBR n } 15.575 \\
\text { Edificações } \\
\text { habitacionais - } \\
\text { Desempenho }\end{array}$ & ISO 15.928 \\
\hline Observação & $\begin{array}{l}\text { Códigos que } \\
\text { já previam } \\
\text { requerimentos } \\
\text { em função de } \\
\text { desempenho }\end{array}$ & $\begin{array}{l}\text { Código com } \\
\text { requisitos de } \\
\text { desempenho de } \\
\text { acordo com sua } \\
\text { finalidade }\end{array}$ & $\begin{array}{l}\text { Dividido em partes } \\
\text { com requisitos de } \\
\text { desempenho para os } \\
\text { sistemas }\end{array}$ & $\begin{array}{l}\text { Requisitos de } \\
\text { desempenho } \\
\text { para edificações } \\
\text { residenciais }\end{array}$ & $\begin{array}{c}\text { Descrição de } \\
\text { desempenho para } \\
\text { casas }\end{array}$ \\
\hline
\end{tabular}

Fonte: Souza (2016). 
Portanto, verifica-se que há tendência mundial para criação e adoção das normas de desempenho, visto que tendem a promover a melhoria dos sistemas construtivos tradicionalmente utilizados e a permitir a adoção de novos, que melhor atendem às necessidades dos usuários, facilitando a comparação entre sistemas distintos, estimulando o setor. Também privilegia a comunicação com o usuário, permitindo que participe do processo de decisão das soluções a serem adotadas, contribuindo para maior conscientização e satisfação do cliente (FOLIENTE, 2000).

\section{APLICABILIDADE DA NORMA DE DESEMPENHO}

Inicialmente é necessário entender como a responsabilidade da aplicação da ND é distribuída entre os principais agentes do setor de construção civil. A responsabilidade de demonstrar a qualidade do produto é do fornecedor. Portanto, cabe aos fornecedores de materiais e produtos comprovar o atendimento às normas técnicas, em geral prescritivas e anteriores à ND. Aos projetistas cabe especificar os requisitos dos materiais e produtos que devem ser utilizados, e às incorporadoras, ou construtoras, comprovar o atendimento à norma de desempenho de seus sistemas e exigir comprovação de atendimento das normas técnicas relativas a materiais e produtos (CÂMARA BRASILEIRA DA INDÚSTRIA DA CONSTRUÇÃO, 2015).

A aplicação da Norma de Desempenho também envolve outros desafios, como mudanças no processo de projeto, no processo de produção, na cadeia de fornecedores e na fiscalização. Segundo Silva et al. (2014), o projeto deve ser o norteador principal para o processo de atendimento à Norma, portanto é necessário maior empenho dos projetistas para que, através do conhecimento dos requisitos solicitados, possam elaborar projetos, especificações de materiais e memoriais mais detalhados

O estudo realizado por Kern, Silva e Kazmierczak (2014) aponta diferentes ou novas exigências aos projetistas para a implementação da ND. Segundo os autores, o envolvimento dos projetistas demonstrou ser o elemento mais importante de todo o processo, pois consiste no principal determinante para que a edificação atinja os critérios de desempenho estabelecidos. Em entrevista com projetistas, estes alegam que a adequação ao conceito de desempenho demanda grande envolvimento e resulta em maior prazo para a elaboração dos projetos, tendo em vista necessidade de maior pesquisa de normas, maior conhecimento técnico de materiais e necessidade de preparação dos profissionais.

Neste contexto, iniciativas visando facilitar o entendimento por partes dos projetistas começam a ganhar força, como a realização de seminários e palestras por universidades e entidades de classes, ou como a publicação de diretrizes ou guias, como o manual para contratação de projetos que instrui quais informações e detalhamentos que os projetos devem possuir para atender à ND (SERVIÇO NACIONAL DE APRENDIZAGEM INDUSTRIAL DE MINAS GERAIS, 2016).

O desafio às empresas construtoras está em garantir que a execução atenda aos requisitos determinados no projeto. A partir da implantação da NBR $n^{0} 15.575 / 2013$, o não atendimento aos requisitos de desempenho e erros de execução podem colocar a empresa construtora em posição vulnerável perante os clientes (KERN; SILVA; KAZMIERCZAK, 2014). Embora a compra de imóveis normalmente ocorra mais pela aparência do que pela qualidade embutida, o proprietário pode recorrer, enquanto no prazo de vida útil, aos ensaios e às análises específicas como comprovação do desempenho, sobre risco de responsabilizar a incorporadora ou construtora por propaganda enganosa e danos morais (CÂMARA BRASILEIRA DA INDÚSTRIA DA CONSTRUÇÃO, 2015).

Segundo Sukster (2005), a integração entre as partes envolvidas é necessária para melhorar o desempenho do setor de construção civil. Com esse objetivo, o autor sugere melhorias nos sistemas de gestão da qualidade e nos 
sistemas de planejamento e controle da produção, que podem ocorrer através de realização de reuniões periódicas (análise de processos visando aspectos de planejamento, qualidade, soluções e melhorias), inclusão de procedimentos de gestão da qualidade em planilhas de planos de médio e curto prazo, utilização de indicadores de avaliação de serviços realizados (identificar problemas e garantir que as tarefas sejam finalizadas no prazo estabelecido e com a qualidade desejada) e treinamento e participação de todos os funcionários na obra, tanto no planejamento como no controle dos serviços.

Quanto à cadeia de fornecedores, os projetistas e construtores entrevistados por Kern, Silva e Kazmierczak (2014) apontam que existe um grande desafio no sentido de apresentar melhorias na adequação de produtos às exigências de desempenho referentes a especificações técnicas, prazo de vida útil e recomendações ao uso e à manutenção, incluindo a disponibilidade de informações. Não existe um programa oficial de incentivo para os fornecedores se adaptarem à NBR nº 15.575/2013. Porém, o Ministério das Cidades trabalha neste objetivo por meio do Programa Brasileiro de Qualidade e Produtividade no Habitat (PBQP-H). Os programas de certificação de produtos (selo Procel) e para edificações (Procel edifica e Selo Casa Azul da Caixa), apesar de estarem relacionados ao desempenho, não estão diretamente associados à Norma.

Segundo a Câmara Brasileira da Indústria da Construção (2015), as fábricas estão caracterizando seus produtos e disponibilizando essas informações em catálogos. Embora em andamento, especialmente no mercado de grandes fornecedores, alguns produtos ainda carecem de informações técnicas, como a falta de esclarecimentos sobre força e torque máximo para acionamento de louças e metais sanitários.

Como incumbência decorrente da norma está a redação de Manual de Uso, Operação e Manutenção (MUOM) para a garantia da vida útil de projeto (VUP), repassando ao usuário a responsabilidade da manutenção do prédio (KERN; SILVA; KAZMIERCZAK, 2014). Assim, cabe ao usuário seguir as recomendações de operação e manutenção, sendo o responsável pela realização e gestão de serviços de manutenção preventiva e corretiva.

Outro desafio na aplicabilidade da ND consiste na melhoria de laboratórios para a realização de ensaios, sendo que a falta de infraestrutura laboratorial para a realização dos ensaios previstos na ND é um forte empecilho para a sua implementação e foi utilizada como argumento para sua postergação (KERN; SILVA; KAZMIERCZAK, 2014).

Neste sentido, uma estratégia do Governo Federal foi o do edital Chamada Pública MCT/MCIDADES/Finep/AT - Sinat - Infraestrutura Laboratorial 10/2010, na busca de projetos voltados ao fortalecimento de infraestrutura laboratorial na área da construção civil, de institutos tecnológicos e de pesquisa para atuar como ITA. Ao total, foram financiadas quatro propostas, duas de instituições sediadas em São Paulo (o Instituto de Pesquisas Tecnológicas do Estado de São Paulo S.A. e o Centro Cerâmico do Brasil já atuantes), uma em Pernambuco (Associação Instituto de Tecnologia de Pernambuco) e uma no Rio Grande do Sul (Universidade do Vale do Rio dos Sinos). Outra iniciativa consistiu no lançamento da Chamada Pública MCT/ MCIDADES/Finep/Ação Transversal - Saneamento Ambiental e Habitação $7 / 2009$, que propôs como um dos temas o desenvolvimento de métodos de ensaio para a avaliação de desempenho de tecnologias inovadoras no âmbito do Sistema Nacional de Avaliação Técnica (Sinat), a partir do trabalho em rede de pesquisa entre diversas instituições de pesquisa brasileiras.

Por fim, segundo Mahl e Andrade (2010), as dificuldades para aplicação da ND incluem também a realização de ensaios no local e em laboratórios, a necessidade de acesso à grande quantidade de normas e a amplitude de algumas avaliações. Portanto, tendo em vista que o desempenho não pode ser considerado como a soma dos elementos que compõem um sistema, a complexidade destes e a dificuldade de se prever resultados de desempenho, é recomendável o investimento em ensaios a fim de garantir os resultados de desempenhos almejados na edificação. 


\section{METODOLOGIA}

Este trabalho fundamentou-se no estudo de caso como estratégia de pesquisa, visto que permite uma investigação de características holísticas e significativas de eventos da vida real (YIN, 2001). A obra estudada consiste num edifício habitacional de alto padrão que foi projetado e construído com a intenção de atender ao nível superior da NBR no 15.575/2013. Tal edificação localiza-se em área nobre da cidade de Novo Hamburgo (RS), com terreno de $3.074,12 \mathrm{~m}^{2}$ e cerca de $18.000 \mathrm{~m}^{2}$ de área construída. É composta por 26 pavimentos, com 32 apartamentos de 2 dormitórios; 32 apartamentos de 3 dormitórios; e 8 apartamentos do tipo loft (Figuras 2 e 3).

Figuras 2 e 3: Imagem renderizada do edifício e fotografia da obra em junho de 2016

Fonte: Site da empresa. Acesso em: 11 ago. de 2016
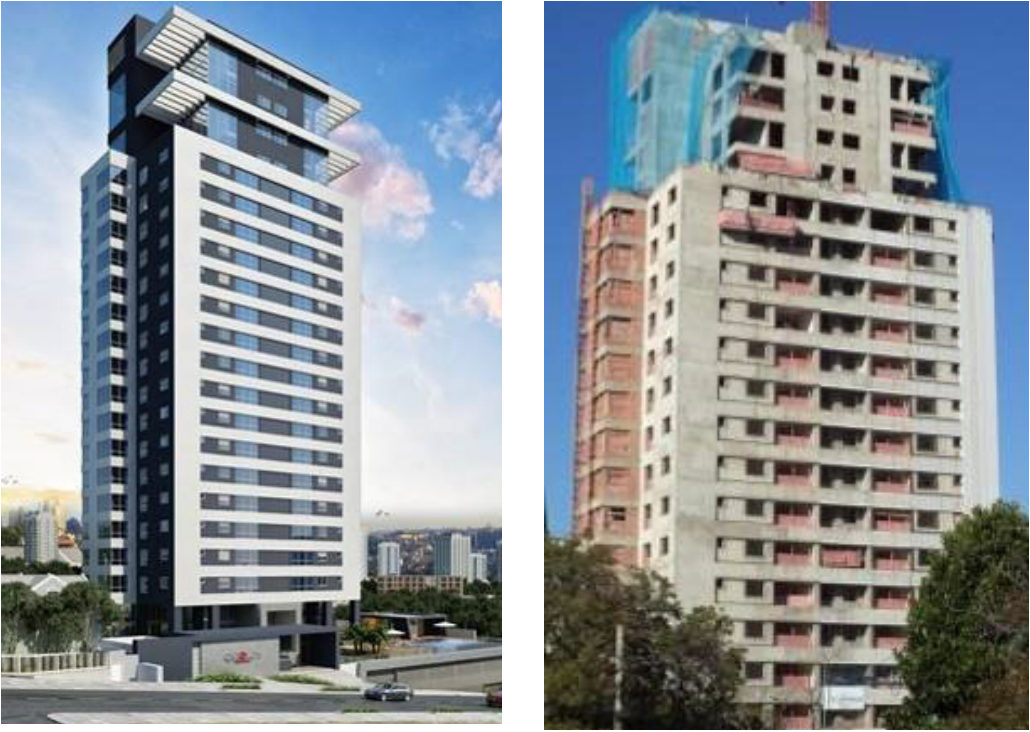

Para identificar as principais mudanças e desafios na implantação do nível superior da ND na edificação estudada, foi necessário dividir a pesquisa em duas etapas. A primeira trata-se de uma análise qualiquantitativa da ND, tendo em vista a complexidade e amplitude da Norma. A segunda consistiu na análise das principais mudanças e desafios observados na implantação do nível superior da Norma, delimitada em aspectos mais relevantes definidos na etapa anterior.

A análise quantitativa consistiu na identificação dos critérios de avaliação e distribuição dos critérios em função dos aspectos e das partes da ND. Em seguida identificou-se quais critérios possuíam mais de um nível de atendimento (mínimo, intermediário e superior) e comparou-se os critérios mínimos e superiores a fim de mensurar quanto o nível superior é mais restritivo e potencialmente mais difícil de ser atendido.

Para a análise qualitativa, buscou-se elencar as relações entre aspectos e partes da Norma com critérios mais exigentes e, assim, focar a pesquisa em elementos mais relevantes. Esta atividade exigiu uma análise mais minuciosa dos critérios da Norma, a fim de identificar quais seriam potencialmente mais difíceis de ser atendidos, quais não se aplicavam à edificação em questão e quais seriam facilmente atendidos. Foram considerados mais difíceis aqueles critérios que exigem mais alterações nos sistemas construtivos previstos ou na rotina da execução da edificação (como análises, elaboração de documentos como o MUOM etc.). Por fim, foi elaborada uma tabela em função dos aspectos e partes na Norma cuja classificação considera "A” aquelas relações que possuem critérios facilmente atendidos; "B”, os que exigem poucas adaptações: e "C”, os que possuíam maior grau de dificuldade de atendimento. 
Para identificar os principais desafios da implementação da ND, primeiramente foi realizada análise voltada às relações dos critérios de avaliação da Norma com a execução da edificação estudada, agrupandose os critérios de avaliação de mesmo aspecto. Identificou-se quantos e quais foram os critérios, inclusive aqueles que não se aplicam à edificação. Buscou-se relacionar cada critério ao principal método de avaliação, etapa da obra e agente envolvido. Os critérios e métodos de avaliação constam na ND, entretanto, para relacioná-los à etapa de obra e ao agente envolvido, foi realizada uma análise que inclui: o projeto arquitetônico e memorial descritivo da edificação; cronograma da obra; cronograma dos ensaios e orientações da ITA para atendimento à ND; observação in loco; e entrevistas sobre obra e ITA. Foram entrevistadas seis pessoas e se questionou como era realizada a avaliação do atendimento à Norma.

A identificação das principais mudanças e desafios foi realizada com base nas relações entre os aspectos e as partes da norma que possuem critérios mais complexos de ser atendidos. Para esta análise foram utilizados: observação in loco na obra e na ITA e entrevistas abertas com o engenheiro responsável pela obra, os colaboradores e os sócios da incorporadora.

\section{RESULTADOS}

\section{Análise quantitativa dos critérios de avaliação da ND: partes da norma e aspectos de desempenho}

A análise quantitativa é realizada através da identificação da quantidade de critérios em função dos aspectos e das partes da Norma, assim como seus totais. A Tabela 2 apresenta a distribuição quantitativa dos critérios da ND, sendo que as linhas apresentam as seis partes da Norma e as colunas, os doze aspectos de desempenho.

Tabela 2 - Distribuição da quantidade de critérios de avaliação da ND em função dos aspectos e das partes da Norma

\begin{tabular}{|c|c|c|c|c|c|c|c|c|c|c|c|c|c|}
\hline $\begin{array}{c}\text { Aspecto de } \\
\text { Desempenho }\end{array}$ & 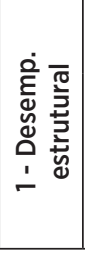 & 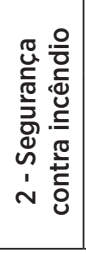 & 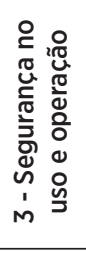 & 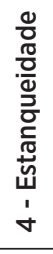 & 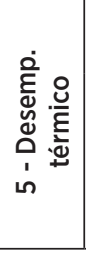 & 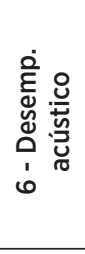 & 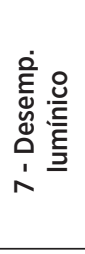 & 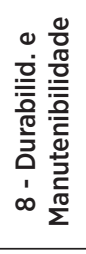 & 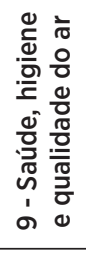 & 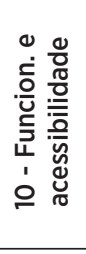 & 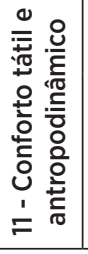 & 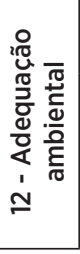 & TOTAL \\
\hline $\begin{array}{l}\text { NBR 15.575-1 Req. } \\
\text { Gerais }\end{array}$ & - & 6 & 2 & 2 & 2 & 3 & 3 & 3 & 3 & 4 & 2 & 1 & 31 \\
\hline $\begin{array}{l}\text { NBR 15.575-2 } \\
\text { Sistemas estruturais }\end{array}$ & 4 & - & - & - & - & - & - & 2 & - & - & - & - & 6 \\
\hline $\begin{array}{l}\text { NBR } 15.575-3 \\
\text { Sistemas de pisos }\end{array}$ & 4 & 8 & 4 & 3 & - & 2 & - & 3 & - & 1 & 1 & - & 26 \\
\hline $\begin{array}{l}\text { NBR 15.575-4 } \\
\text { Sistemas Vedação }\end{array}$ & 7 & 3 & - & 3 & 3 & 2 & - & 3 & - & - & - & - & 21 \\
\hline $\begin{array}{l}\text { NBR } 15.575-5 \\
\text { Sistemas de } \\
\text { coberturas }\end{array}$ & 7 & 3 & 6 & 5 & 1 & 2 & - & 3 & - & 1 & - & - & 28 \\
\hline $\begin{array}{l}\text { NBR 15.575- } \\
6 \text { Sistemas } \\
\text { hidrossanitários }\end{array}$ & 7 & 3 & 8 & 4 & - & 1 & - & 5 & 7 & 4 & 1 & 3 & 43 \\
\hline TOTAL & 29 & 23 & 20 & 17 & 6 & 10 & 3 & 19 & 10 & 10 & 4 & 4 & 155 \\
\hline
\end{tabular}

Fonte: Souza (2016). 
No total, a ND possui 155 critérios de avaliação. Em função das partes da Norma, as que possuem maior quantidade de critérios são, respectivamente: NBR n ${ }^{\circ} 15.575-6$ - sistemas hidrossanitários, com 43 critérios; NBR nº 15.575 1 - requisitos gerais, com 31; NBR $n^{0} 15.575-5$ - sistemas de coberturas, com 28; NBR no 15.575-3 - sistemas de pisos, com 26; NBR 15.575-4 - sistemas de vedação, com 21; e NBR 15.575-2 - sistemas estruturais, com 6 critérios.

Considerando os aspectos de desempenho, os que possuem maior quantidade de critérios são: desempenho estrutural (29), segurança contra incêndio (23), segurança no uso e na operação (20), durabilidade e manutenibilidade (19), estanqueidade (17).

Dos 155 critérios de avaliação, apenas 26 (16,8\%) estabelecem mais de um nível de atendimento (Tabela 3). Embora a quantidade seja pequena, a diferença entre o critério mínimo e superior pode ser relevante para o atendimento à Norma.

Tabela 3 - Comparação entre quantidade total de critérios e total de critérios com níveis de atendimento

\begin{tabular}{|c|c|c|c|}
\hline NBR & $\begin{array}{l}\text { TOTAL DE } \\
\text { CRITÉRIOS }\end{array}$ & $\begin{array}{l}\text { CRITÉRIOS } \\
\text { COM NÍVEIS }\end{array}$ & $\begin{array}{l}\text { ASPECTOS QUE ESTABELECEM NÍVEIS DE ATENDIMENTO } \\
\text { (DESCRIÇÃO DO CRITÉRIO) }\end{array}$ \\
\hline 15.575-1 - Requisitos gerais & 31 & 7 & $\begin{array}{l}\text { Desempenho térmico (temperatura em condições de verão } \\
\text { e inverno), acústico (ruídos gerados por equipamentos } \\
\text { prediais), lumínico (níveis de iluminação natural, fator de luz } \\
\text { diurna e artificial) e durabilidade (vida útil de projeto dos } \\
\text { sistemas que compõem a edificação). }\end{array}$ \\
\hline $\begin{array}{l}15.575-2 \text { - Sistemas } \\
\text { estruturais }\end{array}$ & 6 & 2 & $\begin{array}{l}\text { Desempenho estrutural (resistência à impacto de corpo mole } \\
\text { e duro). }\end{array}$ \\
\hline $\begin{array}{l}15.575-3 \text { - Sistemas de } \\
\text { pisos }\end{array}$ & 26 & 2 & Desempenho acústico (ruído de impacto e ruído aéreo) \\
\hline $\begin{array}{l}\text { 15.575-4 - Sistemas de } \\
\text { vedação }\end{array}$ & 21 & 6 & $\begin{array}{l}\text { Desempenho estrutural (resistência à carga suspensa e } \\
\text { impacto de corpo mole e duro), estanqueidade (à água de } \\
\text { chuva em fachadas e esquadrias), desempenho acústico } \\
\text { (ruídos em fachadas e entre ambientes). }\end{array}$ \\
\hline $\begin{array}{l}15.575-5 \text { - Sistemas de } \\
\text { cobertura }\end{array}$ & 28 & 8 & $\begin{array}{l}\text { Desempenho estrutural (resistência à impacto corpo mole e } \\
\text { duro), estanqueidade (impermeabilidade), durabilidade (vida } \\
\text { útil e estabilidade de cor de telhas), desempenho térmico } \\
\text { (transmitância térmica) e acústico (ruído aéreo e impacto) }\end{array}$ \\
\hline $\begin{array}{l}\text { 15.575-6 - Sistemas } \\
\text { hidrossanitários }\end{array}$ & 43 & 1 & $\begin{array}{l}\text { Desempenho acústico (ruídos gerados por equipamentos } \\
\text { prediais). }\end{array}$ \\
\hline TOTAL & 155 & 26 & \\
\hline
\end{tabular}

Fonte: Souza (2016).

Em relação às partes da ND, dos 26 critérios que estabelecem três níveis de atendimento, 8 são na NBR $n^{\circ} 15.575-5$ - sistemas de coberturas; 7 na NBR $\mathrm{n}^{0}$ 15.575-1 - requisitos gerais; 6 na NBR $\mathrm{n}^{0}$ 15.575-4 - sistemas de vedação; 2 na NBR no ${ }^{0} 15.575-2$ - sistemas estruturais; 2 na NBR no ${ }^{\circ}$ 15.575-3 - sistemas de pisos; e 1 na NBR no 15.575-6 - sistema hidrossanitário. Em relação aos aspectos de desempenho, 8 critérios são relacionados ao desempenho acústico; 7 ao desempenho estrutural; 3 ao desempenho térmico; 3 ao desempenho lumínico; 3 aos critérios de durabilidade; e 2 à estanqueidade.

Embora a quantidade de critérios que possuem nível superior seja apenas $16,8 \%$ do total, podem representar um grande diferencial para uma edificação. Como exemplo, é possível identificar na parte relativa à VUP: os sistemas e partes da edificação no nível superior possuem VUP 50\% maior que o VUP do nível mínimo, podendo representar um ganho econômico para o usuário, pois indica redução no custo de manutenção do edifício ao longo do tempo. Para o desempenho térmico, o nível superior possui uma diferença de $4{ }^{\circ} \mathrm{C}$ do nível mínimo para condições de verão nas zonas bioclimáticas de 1 a 7 e para condições de inverno nas zonas 1 a 5 , o que pode representar redução da energia necessária à climatização artificial do ambiente. 
Quanto ao desempenho lumínico, a diferença entre os níveis pode ser do dobro de iluminação natural e artificial exigida. Em determinados ambientes como banheiros, corredores, garagens e escadarias não há exigências para iluminamento natural no nível mínimo, mas há para o nível intermediário e superior. O desempenho acústico é medido em $\mathrm{dB}$, que é uma unidade logarítmica, sendo que nesta medida um aumento de $6 \mathrm{~dB}$ significa a duplicação da intensidade sonora, mas o ouvido só percebe a duplicação de volume com um aumento de 10dB (GUYTON, 1967 e GRANDJEAN, 1998 apud GONÇALVES et al., 2011). A diferença no desempenho acústico pode chegar a $6 \mathrm{~dB}$ em equipamentos prediais e sistemas hidrossanitários, ou seja, metade da intensidade e sensação de cerca de 60\% menor. Em sistemas de pisos, vedações e coberturas essa diferença pode ser maior ou igual a $10 \mathrm{~dB}$, ou seja, metade do volume audível.

No desempenho estrutural há diferenças entre as exigências em impactos de corpo mole para sistemas estruturais, pisos, vedação, coberturas acessíveis e sistemas hidrossanitários aparentes. Em geral, devem resistir a impactos 33\% maiores que o mínimo (480, 720 ou 960J de acordo com o elemento a ser analisado). Em impactos de corpo duro para os mesmos sistemas a carga é a mesma, no entanto, admite-se, no nível superior, apenas mossas com profundidade menor ou igual a $2 \mathrm{~mm}$ nas menores energias de impacto. Em sistemas de vedação, a exigência relativa às cargas de peças suspensas é 50\% maior no nível superior. Sistemas de coberturas, no nível superior, devem resistir à impactos, que simulam a ação de granizo, 150\% maiores que o mínimo.

$\mathrm{Na}$ estanqueidade em sistemas de vedação o nível superior não permite manchas, enquanto o nível mínimo permite de 5 a 10\% de manchas de umidade na face oposta à incidência de água, e os sistemas de coberturas devem apresentar estanqueidade e durabilidade $240 \%$ maior que o mínimo. Embora a proporção de critérios com níveis seja pequena, o nível superior é mais restritivo e pode constituir dificuldade no atendimento à ND.

\section{Análise qualitativa da Norma de Desempenho: complexidade de atendimento dos critérios no nível superior}

A Tabela 4 apresenta a classificação dos critérios em função da complexidade de atendimento da ND no nível superior, considerando " $\mathrm{A}$ " aqueles que são facilmente atendidos; "B”, os que exigem poucas adaptações; e "C", os que possuem maior grau de dificuldade de atendimento, exigindo mudanças significativas nos sistemas previstos para a edificação ou na rotina da execução da edificação. As relações que não possuem classificação são aquelas que não possuem critérios de avaliação ou os critérios não se aplicam à edificação estudada.

Segundo a avaliação qualitativa realizada, as quatro primeiras partes da ND foram avaliadas como mais complexas de serem atendidas, a saber: requisitos gerais (segurança contra incêndio, desempenho térmico, durabilidade e manutenibilidade), sistemas estruturais (desempenho estrutural, durabilidade e manutenibilidade), sistemas de pisos (desempenho estrutural, segurança contra incêndio, desempenho acústico, durabilidade e manutenibilidade) e sistemas de vedação desempenho estrutural, segurança contra incêndio, estanqueidade, desempenho térmico, desempenho acústico, durabilidade e manutenibilidade).

\section{Principais desafios no atendimento do nível superior da ND}

A partir da análise qualitativa, os aspectos de desempenho selecionados para identificar os principais desafios de aplicação da ND foram: desempenho estrutural, segurança contra incêndio, estanqueidade, desempenho térmico, desempenho acústico, durabilidade e manutenibilidade. As partes da norma 
avaliadas foram: $\mathrm{NBR}^{0}{ }^{0} 15.575-1$ requisitos gerais, $\mathrm{NBR} \mathrm{n}^{0} 15.575-2$ sistemas estruturais, NBR $n^{\circ} 15.575-3$ sistemas de pisos e NBR $n^{0} 15.575-4$ sistemas de vedação.

Tabela 4: Avaliação da complexidade do atendimento de critérios de avaliação em função dos aspectos e das partes da Norma

\begin{tabular}{|c|c|c|c|c|c|c|c|c|c|c|c|c|}
\hline Aspecto de Desempenho & & & & & & & & & & & & \\
\hline Partes da ND & 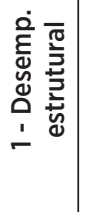 & 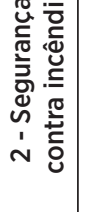 & 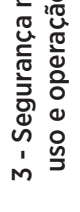 & 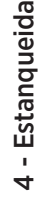 & 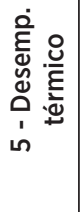 & 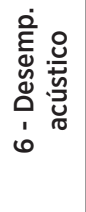 & 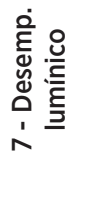 & 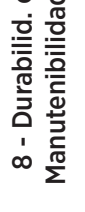 & 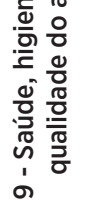 & 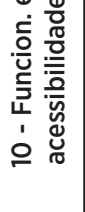 & 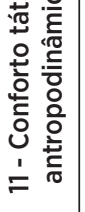 & 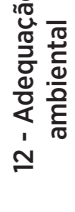 \\
\hline NBR 15.575-1 Req. Gerais & - & C & B & A & C & A & B & C & B & B & B & B \\
\hline $\begin{array}{c}\text { NBR 15.575-2 Sistemas } \\
\text { estruturais }\end{array}$ & C & & & & & & & C & - & - & - & - \\
\hline $\begin{array}{c}\text { NBR 15.575-3 Sistemas de } \\
\text { pisos }\end{array}$ & C & C & B & $B$ & - & C & - & C & - & A & A & - \\
\hline $\begin{array}{c}\text { NBR 15.575-4 Sistemas } \\
\text { Vedação }\end{array}$ & C & C & - & C & C & C & - & C & - & - & - & - \\
\hline $\begin{array}{c}\text { NBR } 15.575-5 \text { Sistemas de } \\
\text { coberturas }\end{array}$ & $A$ & A & B & A & A & B & - & B & - & A & - & - \\
\hline $\begin{array}{l}\text { NBR 15.575-6 Sistemas } \\
\text { hidrossanitários }\end{array}$ & B & A & B & A & - & A & - & B & B & A & A & B \\
\hline
\end{tabular}

Fonte: Souza (2016).

\section{Desempenho estrutural}

Dos 29 critérios no aspecto de desempenho estrutural, 7 não se aplicam à obra em estudo, restando 22 critérios que devem ser atendidos. As principais mudanças e desafios ocorridos na obra para atendimento da ND no nível superior estão apresentadas na Tabela 5.

Tabela 5: Principais mudanças e responsáveis em relação aos critérios de desempenho estrutural

\begin{tabular}{|c|c|c|}
\hline \multicolumn{2}{|c|}{ PARTES DA ND } & PRINCIPAIS ALTERAÇÕES \\
\hline \multicolumn{2}{|c|}{2 - Sistemas estruturais } & $\begin{array}{l}\text { Ensaios para avaliação da resistência, carga horizontal e } \\
\text { vertical em parapeito, e corpo mole e duro em parapeitos e } \\
\text { outras estruturas. Controle tecnológico total do concreto. }\end{array}$ \\
\hline \multicolumn{2}{|c|}{3 - Sistemas de pisos } & $\begin{array}{l}\text { Ensaios para avaliação da resistência, como corpo duro e } \\
\text { carga concentrada em pisos. }\end{array}$ \\
\hline \multirow{2}{*}{ 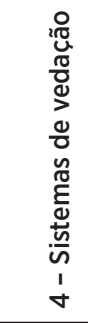 } & Interna & $\begin{array}{l}\text { Ensaios para avaliação da capacidade de suporte de peças } \\
\text { suspensas, impacto de corpo duro e mole, ações transmitidas } \\
\text { por portas. Recomendações no MUOM como o uso de buchas } \\
\text { específicas para cargas suspensas. }\end{array}$ \\
\hline & Externa & $\begin{array}{l}\text { Ensaios para avaliação da resistência à impacto de corpo } \\
\text { duro e mole (mais exigentes) e ações horizontais, verticais e } \\
\text { impactos em parapeitos. }\end{array}$ \\
\hline
\end{tabular}

Fonte: Souza (2016).

As principais mudanças e desafios encontrados se referem à realização de ensaios, tradicionalmente não realizado anteriormente, tais como: agressividade do solo, levantamentos das características do local e os riscos pertinentes do entorno, ensaios de resistência mecânica em parapeitos e outras estruturas, ensaios de resistência mecânica dos pisos, sendo que a ITA atuou como principal responsável. 
Além dos ensaios, cabe comentar o acompanhamento da ITA na execução da armadura, formas e cimbramento e o controle tecnológico do concreto que era parcial por amostragem em outras obras da incorporadora, passou a ser total nesta obra.

Em relação aos sistemas de vedação, observou-se a adoção de bloco estrutural cerâmico com $19 \mathrm{~cm}$ de largura e $15 \mathrm{Mpa}$. Em alguns casos, foi utilizado reboco de até $5 \mathrm{~cm}$ e preenchimento interno com argamassa com grande proporção de areia para atendimento dos critérios de isolamento acústico, especialmente em paredes de divisa entre áreas privativas. Essa solução pode ter colaborado para o atendimento de critérios de capacidade de suporte de peças suspensas, que só pode ser atingido após o uso de buchas específicas para esta finalidade.

\section{Segurança contra incêndio}

Dos 23 critérios relacionados a este aspecto, 3 não se aplicam à edificação em questão, visto que esta não apresenta sistema de cobertura com telhado ou similar. A Tabela 6 apresenta as principais mudanças ocorridas para o atendimento no aspecto de segurança contra incêndio.

Tabela 6: Principais mudanças e responsáveis em relação aos critérios de segurança contra incêndio

\begin{tabular}{|c|c|c|}
\hline \multicolumn{2}{|r|}{ PARTES DA ND } & PRINCIPAIS ALTERAÇÕES \\
\hline 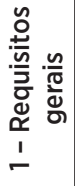 & $\begin{array}{l}\text { Projetos } \\
\text { complementares }\end{array}$ & $\begin{array}{l}\text { Análises quanto às instalações elétricas, de gás, rotas de } \\
\text { fuga, risco de colapso estrutural, sistemas de extinção e } \\
\text { sinalização de incêndio e de proteção contra descargas } \\
\text { atmosféricas. }\end{array}$ \\
\hline \multicolumn{2}{|c|}{3 - Sistemas de pisos } & $\begin{array}{l}\text { Ensaios de reação ao fogo. Alguns pontos em que havia } \\
\text { previsão de lajes nervuradas houve substituição por laje } \\
\text { maciça. }\end{array}$ \\
\hline \multicolumn{2}{|c|}{4 - Sistemas de vedação } & Ensaios de reação e resistência ao fogo. \\
\hline
\end{tabular}

Fonte: Souza (2016).

Embora o enfoque desta etapa do trabalho seja a execução, observouse que a parte relativa aos requisitos gerais exigiu inúmeras análises e detalhamentos pertinentes aos projetos complementares, isto repercutiu na incorporadora que teve de exigir mais dos projetistas e culminou na colaboração da execução destes projetos ou na execução. Quanto aos sistemas de pisos, observou-se que a laje nervurada provavelmente não atingiria o tempo requerido de resistência ao fogo (TRRF) estabelecido, portanto, foi substituída pela laje maciça. Houve compartimentação deste sistema de forma a privilegiar áreas que viessem a servir para evacuação das pessoas do edifício. Em relação aos sistemas de vedação, foram realizados ensaios de reação e resistência dos sistemas, principalmente, pois nas paredes limítrofes de unidades privativas foi usado reboco com EVA.

O maior desafio para este aspecto foi a realização dos ensaios, visto que estes exigem investimento de material, serviços e insumos. O ensaio de resistência ao fogo exige que seja confeccionada uma parede de 3x3m em laboratório e que esta seja exposta ao fogo por até $4 \mathrm{~h}$, depois disso ela é demolida e são analisados os dados.

\section{Estanqueidade}

Dos 17 critérios relativos à estanqueidade, 6 não se aplicam à edificação em questão, visto que esta não apresenta sistema de cobertura com telhado ou similar. A Tabela 7 apresenta as principais mudanças ocorridas para o atendimento dos critérios que se referem ao aspecto estanqueidade e que se relacionam ao sistema de vedação, considerando paredes internas e externas. 
Tabela 7: Principais mudanças e agentes envolvidos em relação aos critérios de estanqueidade

\begin{tabular}{|c|c|c|}
\hline \multicolumn{2}{|c|}{ PARTE DA ND } & PRINCIPAIS ALTERAÇÕES \\
\hline \multirow{2}{*}{ 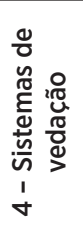 } & Interna & $\begin{array}{l}\text { Ensaio de infiltração de umidade em vedações devido ao uso } \\
\text { (áreas molhadas e molháveis). }\end{array}$ \\
\hline & Externa & $\begin{array}{l}\text { Ensaio de infiltração de água de chuva em fachadas, } \\
\text { principalmente na junção entre a janela e a parede. } \\
\text { Observou-se o uso de janelas com vidro duplo, de melhor } \\
\text { vedação e maior cuidado na vedação nas junções. }\end{array}$ \\
\hline
\end{tabular}

Fonte: Souza (2016).

A complexidade de atendimento da estanqueidade envolve a realização de ensaios, exigindo cuidado maior na interface entre esquadrias e sistema de vedação, resultando em consumo maior de selante. Para esta edificação foram especificadas esquadrias fabricadas em alumínio anodizado com persianas e vidros duplos.

Para as paredes internas, no memorial descritivo da edificação consta revestimento cerâmico para banheiros e pintura acrílica com detalhes em cerâmica para as cozinhas e áreas de serviço, os ensaios realizados indicam o quanto tais revestimentos permitem a estanqueidade destas áreas.

O maior desafio neste aspecto consistiu na vedação das junções entre a janela e a parede, e em evitar a infiltração da umidade em vedações, sendo que este último ensaio falhou mais de uma vez.

\section{Desempenho térmico}

Todos os 6 critérios de desempenho térmico possuem três níveis de atendimento (mínimo, intermediário e superior) e se aplicam à edificação estudada. A Tabela 8 apresenta as principais mudanças ocorridas para atendimento do desempenho térmico.

Tabela 8: Principais mudanças e responsáveis em relação ao desempenho térmico

\begin{tabular}{|c|c|c|}
\hline \multicolumn{2}{|c|}{ PARTE DA ND } & PRINCIPAIS ALTERAÇÕES \\
\hline $\begin{array}{l}1 \text { Requisitos } \\
\text { gerais }\end{array}$ & Projeto & Simulação computacional da edificação. \\
\hline $\begin{array}{l}4 \text { - Sistemas } \\
\text { de vedação }\end{array}$ & Externa & $\begin{array}{l}\text { Uso de cores mais escuras ou tintas especiais. } \\
\text { Esquadrias com vidro duplo e persianas. }\end{array}$ \\
\hline
\end{tabular}

Fonte: Souza (2016).

A simulação computacional do desempenho térmico da edificação apontou quais pontos da edificação apresentaram melhor desempenho e quais poderiam não passar. Foi indicado que os últimos pavimentos (principalmente os lofts) seriam mais difícieis de atender ao desempenho no inverno, sendo necessário o uso de tintas com cores mais escuras ou especiais, no sentido de permitir maior absortância da radiação solar. Quanto às esquadrias, o vidro duplo possibilitou aumento na resistência térmica e auxiliou o atendimento ao desempenho no inverno, já a persiana permitiu o bloqueio da radiação solar, que está mais voltado ao atendimento do desempenho no verão.

Considera-se que o maior desafio deste aspecto está na simulação computacional, visto que além da elaboração do modelo do edifício, é necessário incluir diversos parâmetros para a realização deste.

\section{Desempenho acústico}

Os 10 critérios relacionados a este aspecto são avaliados por meio de ensaios. Embora seja possível que os critérios possam ser avaliados pela especificação dos produtos, observou-se a carência destas informações 
por parte dos fornecedores. A Tabela 9 apresenta as principais mudanças ocorridas para atendimento do desempenho térmico.

Tabela 9: Principais mudanças e responsáveis em relação aos critérios de desempenho acústico

\begin{tabular}{|c|c|c|}
\hline \multicolumn{2}{|r|}{ PARTE DA ND } & PRINCIPAIS ALTERAÇÕES \\
\hline \multirow{2}{*}{ 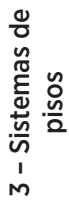 } & $\begin{array}{l}\text { Limítrofes com } \\
\text { dormitório ou áreas de } \\
\text { uso coletivo }\end{array}$ & Laje maciça com manta acústica e contrapiso. \\
\hline & $\begin{array}{l}\text { Outras áreas limítrofes } \\
\text { com áreas privativas }\end{array}$ & Laje maciça com manta acústica e contrapiso. \\
\hline \multirow{2}{*}{ 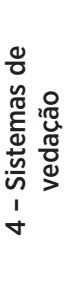 } & $\begin{array}{l}\text { Limítrofes com } \\
\text { dormitório ou áreas de } \\
\text { uso coletivo }\end{array}$ & $\begin{array}{l}\text { Bloco estrutural de } 19 \mathrm{~cm} \text { de espessura preenchido } \\
\text { com argamassa com grande proporção de areia e } \\
\text { reboco com EVA de até } 5 \mathrm{~cm} \text { de espessura. Uso de } \\
\text { manta acústica em forros de gesso. }\end{array}$ \\
\hline & Outras áreas limítrofes & $\begin{array}{l}\text { Bloco estrutural de } 19 \mathrm{~cm} \text { de espessura e reboco } \\
\text { com EVA de até } 5 \mathrm{~cm} \text {. Esquadrias com vidro duplo e } \\
\text { persianas. }\end{array}$ \\
\hline
\end{tabular}

Fonte: Souza (2016).

Este aspecto motivou as maiores mudanças na edificação. Adotou-se, no sistema de pisos, o uso de lajes maciças com até $12 \mathrm{~cm}$ de espessura (ao invés de lajes pré-moldadas ou lajes protendidas), mantas acústicas e contrapiso de até $8 \mathrm{~cm}$ de espessura. Já nos sistemas de vedação, adotou-se o uso de blocos estruturais de $19 \mathrm{~cm}$ de espessura, em alguns casos preenchidos com argamassa com grande proporção de areia, com reboco com EVA de até $5 \mathrm{~cm}$, uso de manta acústica nos forros de gesso e esquadrias com vidro duplo e persianas.

Em ambos os casos (pisos e vedações verticais) é notório o aumento das seções destes sistemas, sendo, nos sistemas de pisos, um acréscimo de até $22 \mathrm{~cm}$ e na vedação vertical de até $27 \mathrm{~cm}$, em comparação a obras anteriores da empresa. Tal fato se justifica, pois um dos fatores que mais influenciam o aumento do isolamento acústico é a massa. Entretanto, tal solução implica em maior carga e possível redução da área útil dos ambientes. Além desta análise, é importante ressaltar que surgiram novos elementos (como as mantas acústicas nos pisos e forro de gesso), novos serviços e métodos construtivos. Os desafios relacionados a este aspecto estão principalmente relacionados à inclusão de novos elementos e à execução de novos procedimentos de trabalho relacionados à eles.

\section{Durabilidade e manutenibilidade}

Dos 19 critérios relativos à estanqueidade, 2 não se aplicam a este edifício em questão. A Tabela 10 apresenta as principais mudanças ocorridas em relação aos critérios mais relevantes para o aspecto de durabilidade e manutenibilidade, sendo que estes critérios possuem maiores relações com os requisitos gerais e sistemas estruturais, pisos e vedações.

Observou-se grande envolvimento da incorporadora para detalhar e especificar sistemas que pudessem atingir a VUP estipulada pela norma, tal como envolvimento para desenvolver o MUOM da edificação, a fim de orientar o uso correto dos equipamentos e sistemas da edificação e quanto às manutenções necessárias. Quanto aos sistemas estruturais, houve um aumento na classe do concreto e na espessura do cobrimento da armadura, ambos em função de atender aos 75 anos de vida útil prevista para a edificação.

Em relação aos sistemas de pisos, adotou-se cerâmicas com maior resistência à abrasão, principalmente em áreas de uso coletivo. Já para as áreas molhadas ou molháveis, foi necessário a verificação da umidade e o ataque químico. Quanto ao sistema de vedação, houve o ensaio com ação do calor e choque térmico, a fim de avaliar se este sistema atingiria a VUP. 
Tabela 10: Principais mudanças e responsáveis em relação aos critérios de durabilidade e manutenibilidade

\begin{tabular}{|c|c|c|}
\hline \multicolumn{2}{|c|}{ PARTE DA ND } & PRINCIPAIS ALTERAÇÕES \\
\hline & Projetos & Detalhamentos e especificações para atingir a VUP estipulada pela norma. \\
\hline 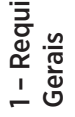 & MUOM & $\begin{array}{l}\text { Descrição do uso correto, informações sobre as manutenções preventivas e } \\
\text { corretivas de todas as partes e elementos da edificação. }\end{array}$ \\
\hline
\end{tabular}

2 - Sistemas estruturais

Aumento na classe do concreto e cobrimento da armadura.

\begin{tabular}{|c|c|c|}
\hline \multirow{2}{*}{ 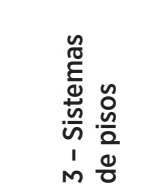 } & Áreas secas & Ensaio de resistência ao desgaste ao uso (abrasão). \\
\hline & $\begin{array}{l}\text { Áreas molhadas ou } \\
\text { molháveis }\end{array}$ & Ensaio de resistência à abrasão, à umidade e ao ataque químico. \\
\hline $\begin{array}{l}4 \text { - Sistemas } \\
\text { de vedação }\end{array}$ & Externa & Ensaio com ação de calor e choque térmico. \\
\hline
\end{tabular}

Fonte: Souza (2016).

Constata-se como o maior desafio deste aspecto a busca de como atender ao VUP da estrutura para 75 anos, pois as normas nacionais não possuem parâmetros para tal. Entretanto, após procurar em normas internacionais, foi evidenciado que havia uma relação da durabilidade com o cobrimento e a classe do concreto para estruturas em concreto armado.

\section{CONCLUSÕES}

Atualmente o desempenho das edificações tem sido tema amplamente discutido, o que pode ser obervado em normas e trabalhos acadêmicos nacionais e internacionais. Iniciativas, como a Norma de Desempenho, têm sido importantes estratégias para a definição de parâmetros de desempenho para as edificações e os métodos de avaliação. No entanto, a implantação da Norma em questão é desafiadora devido à complexidade e abrangência que envolve.

A partir da análise quantitativa dos critérios da ND em relação às partes da norma e aos aspectos de desempenho, é possível observar que dos 155 critérios de avaliação, as partes que mais possuem critérios são, respectivamente: NBR $n^{0} 15.575-6$ - sistemas hidrossanitários; NBR $n^{\circ}$ 15.575-1 - requisitos gerais, sistemas de coberturas, sistemas de pisos, sistemas de vedação e sistemas estruturais. Quanto à distribuição nos aspectos, os que possuem maior quantidade de critérios são: desempenho estrutural, segurança contra incêndio, segurança no uso e operação, durabilidade e manutenibilidade, e estanqueidade. Dos 155 critérios de avaliação, apenas 26 estabelecem três níveis de atendimento (inferior, intermediário e superior).

A análise qualitativa da ND, em termos de complexidade de atendimento, sugere que as quatro primeiras partes da ND são mais complexas: requisitos gerais, sistemas estruturais, sistemas de pisos e sistemas de vedação. Ainda, embora quantitativamente o número de critérios que estabelecem três níveis de atendimento seja pequeno (16\%), a diferença de desempenho entre os níveis inferior e superior é expressiva e pode representar um grande diferencial para uma edificação o atendimento do nível superior.

A partir da análise da aplicação da ND no empreendimento estudado, é possível observar o expressivo número de ensaios realizados na ITA, que possuiu papel relevante e atuou como principal agente no atendimento a muitos critérios, e a adoção de novas tecnologias ou materiais não utilizados em obras anteriores pela empresa construtora. 


\section{REFERÊNCIAS}

ASSOCIAÇÃO BRASILEIRA DE NORMAS TÉCNICAS. NBR 15.575-1: Edificações habitacionais - Desempenho. Parte 1: Requisitos gerais. Rio de Janeiro: ABNT, 2013.

BLACHÉRE, G. Saber construir habitabilidad, durabilidad, economía de los edificios. Barcelona: Editores Técnicos Associados, 1967

BONDUKI, N. G. Origens da habitação social no Brasil: arquitetura moderna, lei do inquilinato e difusão da casa própria. São Paulo: Estação Liberdade, 2004.

BORGES, C. A. M.; SABBATINI, F.H. O conceito de desempenho de edificações e a sua importância para o setor da construção civil no Brasil. São Paulo: EPUSP 2008. (Boletim Técnico da Escola Politécnica da USP, Departamento de Engenharia de Construção Civil, BT/PCC/515).

Dúvidas sobre a norma de desempenho - especialistas respondem às principais dúvidas e elencam requisitos de suporte para elaboração de projetos. Brasília, DF: CBIC, 2015. 161 p.

CAIXA ECONÔMICA FEDERAL. Norma de desempenho da construção trouxe mais qualidade para habitações. São Paulo, 5 nov. 2014. Disponível em: <https://goo.gl/ Zariz2>. Acesso em: 20 dez. 2017.

FOLIENTE, G. C. Developments in performance-based building codes and standards. Forest Products Journal, Peachtree Corners, v. 50, n. 7-8, p.12-21, jul./ ago. 2000

GONÇALVES, O. M. et al. Normas técnicas para avaliação de sistemas construtivos inovadores para habitações. Coletânea habitare, Rio de Janeiro, v. 3, p. 42-53, 2003.

GONÇALVES, F. B. et al. Avaliação dos garçons à exposição da pressão sonora em ambientes fechados com música ao vivo. In ENCONTRO NACIONAL DE ENGENHARIA DE PRODUCÃ̃O, 31., 2011, Belo Horizonte. Anais... Belo Horizonte: ENEGEP, 2011.

KERN, A. P.; SILVA, A.; KAZMIERCZAK, C. S. O processo de implantação de normas de desempenho na construção: um comparativo entre a Espanha (CTE) e Brasil
(NBR 15575/2013). Gestão e Tecnologia de Projetos, São Paulo, v. 9, n. 1, p. 1-13, jan./jun. 2014.

MAHL, R. E.; ANDRADE, J. J. O. Aplicabilidade da norma NBR 15.575/2008 edifícios habitacionais de até cinco pavimentos desempenho: estudo de caso e análise crítica. In: ENCONTRO NACIONAL DE TECNOLOGIA DO AMBIENTE CONSTRUÍDO, 13., 2010, Canela. Anais... Canela: ENTAC, 2010.

MARICATO, E. Habitação e cidade. 5. ed. São Paulo: Atual, 1999. (Coleção Espaço \& Debate)

NAKAMURA, J. Minha casa na mira. Revista Construção Mercado, São Paulo, v. 132, jul. 2012.

SERVIÇO NACIONAL DE APRENDIZAGEM INDUSTRIAL DE MINAS GERAIS. Manual para contratação de projetos para o desempenho de edificações habitacionais. Belo Horizonte, 2016. 260 p.

SERRA, G. G. Post-occupancy evaluation at the urban scale in Brazil. In: PREISER, W. F. (Ed.). Building evaluation. Nova York: Plenum Press, 1989. p. 307-315.

SILVA, A. T. et al. Novas exigências decorrentes de programas de certificação ambiental de prédios e normas de desempenho. Arquitetura Revista, São Leopoldo, v. 10, n. 2, jul./dez. 2014.

SOUZA, J. L. P. Desafios na implantação do nível superior da norma de desempenho em edificação residencial em novo Hamburgo/RS. 2016. 111 f. Dissertação (Mestrado em Engenharia Civil) - Programa de Pós-graduação em Engenharia Civil, Universidade do Vale do Rio dos Sinos, São Leopoldo, 2016.

SUKSTER, R. A integração entre o sistema de gestão da qualidade e o planejamento e controle da produção em empresas construtoras. 2005. $158 \mathrm{f}$. Dissertação (Mestrado Profissionalizante em Engenharia) - Universidade Federal do Rio Grande do Sul, Porto Alegre, 2005.

YIN, R. K. Estudo de caso: planejamento e métodos. 2. ed. Porto Alegre: Bookman, 2001. $205 \mathrm{p}$.
Jonas Leonardo Pessanha de Souza jlpsengenharia@gmail.com

Andrea Parisi Kern apkern@unisinos.br

Bernardo Fonseca Tutikian bftutikian@unisinos.br 
